\title{
Revista de Empreendedorismo e Gestão de Pequenas Empresas
}

https://doi.org/10.14211/regepe.v8i1.1199

\section{APLICAÇÃO DE FERRAMENTAS DE APOIO GERENCIAL CONTÁBIL EM UMA MICROEMPRESA DE CONFECÇÕES}

Recebido: $14 / 04 / 2018$

Aprovado: 16/10/2018

\author{
${ }^{1}$ Filippi Mickael Martini Honorio \\ 2Simone Zuconelli Bonemberger
}

\section{RESUMO}

O objetivo deste estudo foi identificar como as ferramentas gerenciais selecionadas podem auxiliar na gestão empresarial de uma microempresa. O caso estudado foi um comércio de confecções, localizado na região Oeste do Paraná. O trabalho foi realizado no período de maio a dezembro de 2017 e compreendeu atividades direcionadas à gestão da empresa, especificamente a aplicação e análise das seguintes ferramentas: a) Modelo Canvas de Negócios, que serviu como um diagnóstico das necessidades principais da microempresa para os pesquisadores e como uma reflexão e direcionamento sobre o negócio para os empresários; b) Formação de Preço de Venda, que demonstrou a aplicabilidade de um método prático e eficiente na identificação de produtos que podem ter seus preços ajustados, bem como os produtos com maior rentabilidade e os que devem deixar de ser ofertados; e c) o Fluxo de Caixa Projetado, que permitiu aos gestores terem uma visão de suas contas a pagar e a receber em um período maior de tempo, e planejar ações para reduzir ou evitar o endividamento. Quanto a tipologia do estudo, esta pesquisa foi classificada como exploratória quanto aos objetivos, estudo de caso quanto aos procedimentos e qualitativa quanto à abordagem do problema, utilizando a triangulação de dados para a análise do caso, cruzando dados da teoria e conceitos das ferramentas gerenciais, documentos e relatórios da empresa e observação direta com entrevistas informais. O estudo prático apontou que as ferramentas gerenciais aplicadas auxiliam na geração de informações úteis para o planejamento e a tomada de decisão dos gestores e que a forma de gestão atual necessita de mudanças, pois o acompanhamento do negócio é premissa para o alcance do sucesso e do lucro.

Palavras-chave: Microempresa. Modelo Canvas de Negócios. Formação de Preço de Venda. Fluxo de Caixa.

\footnotetext{
${ }^{1}$ Graduando em Ciências Contábeis pela Universidade Estadual do Oeste do Paraná - UNIOESTE, Paraná, (Brasil). E-mail: filippimmhonorio@gmail.com Orcid id: https://orcid.org/0000-0002-3683-1119

${ }^{2}$ Mestra em Administração pela Universidade Estadual do Oeste do Paraná - UNIOESTE, Paraná, (Brasil). E-mail: simonezuconelli@hotmail.com Orcid id: https://orcid.org/0000-0002-8797-7556
} 


\title{
APPLICATION OF SUPPORTING TOOLS FOR ACCOUNTING MANAGEMENT IN A MICRO ENTERPRISE OF MANUFACTURING
}

\begin{abstract}
The objective of this study was to identify how the selected managerial tools can assist in the micro enterprise business management. The case studied was a clothing trade, located in the western region of Paraná. The work was carried out from May to December of 2017 and comprised activities directed to the management of the company, specifically the application and analysis of the following tools: a) Business Canvas Model, which served to the researchers as a diagnosis of the micro company's main needs and as a reflection and direction on the business to the entrepreneurs; b) Sales Price Formation, which demonstrated the applicability of a practical and efficient method to identify products that can have their adjusted prices, as well as the products with higher profitability and those that should no longer be offered; and c) the Projected Cash Flow, which allowed managers to have a view of their accounts payable and receivable over a longer period of time, and to plan actions to reduce or avoid indebtedness. As for the typology of the study, this research was classified as exploratory regarding the objectives, case study regarding the procedures and qualitative approach to the problem, using triangulation of data for a case analysis, crossing data from theory and concepts of management tools, documents and company reporting and direct observation with informal interviews. The practical study pointed out that the applied management tools assist in the generation of information useful for planning and decision making of managers, and that the current management needs to be changed, since the monitoring of the business is premise for the reach of the success and profit.
\end{abstract}

Keywords: Micro Enterprise. Business Canvas Template. Sales Price Formation. Cash Flow. 


\section{INTRODUÇÃO}

O desenvolvimento da Contabilidade em toda a sua história esteve intimamente ligado ao desenvolvimento econômico, às transações sociopolíticas e socioculturais experimentadas em cada época (Nagatsuka, \& Teles, 2002). O homem foi sentindo a necessidade de aperfeiçoar seu instrumento de avaliação da situação patrimonial, ao mesmo tempo em que as atividades econômicas foram tornando-se mais complexas.

Deste modo, destaca-se que a Contabilidade Gerencial tem papel fundamental na gestão das empresas, pois é relacionada ao fornecimento de informação contábil como ferramenta para administração, buscando fornecer as informações necessárias para a gestão financeira e para os administradores (Crepaldi, 1998).

As ferramentas gerencias compõe o sistema de controle gerencial, no entanto, as combinações de ferramentas a serem adotadas variam entre as organizações conforme as necessidades dos gestores (Frezatti, 2005).

Quando um negócio já está em andamento e os gestores desejam rever ou realizar um planejamento, é recomendado a aplicação de uma ferramenta de diagnóstico empresarial. O modelo Canvas de negócio ou Business Model Canvas, desenvolvido por Osterwalder e Pigneur (2011), caracteriza-se como uma representação dos elementos principais de um empreendimento, em específico: que valor deseja entregar aos seus clientes e como se dará a relação entre os envolvidos no mercado e a empresa. O modelo de negócio orientará a empresa na definição e implementação de estratégias, por meio de estruturas, processos e sistemas definidos (Osterwalder, \& Pigneur, 2011).

Outra ferramenta importante para qualquer empresa é o fluxo de caixa, que apresenta-se como um dos instrumentos mais eficazes na gestão financeira, permitindo ao administrador planejar, organizar, coordenar, dirigir e controlar os recursos financeiros para um determinado período, influenciando o processo de tomada de decisão (Toledo Filho, Oliveira, \& Spessatto, 2010). O fluxo de caixa possibilita programar e acompanhar as entradas e as saídas de recursos financeiros, de forma que a empresa possa operar de acordo com os objetivos e as metas determinadas em curto prazo para gerenciar o capital de giro e em longo prazo para fins de investimentos (Toledo Filho, Oliveira, \& Spessatto, 2010).

Uma ferramenta gerencial que também merece destaque é a formação do preço de vendas, que não visa apenas ao aumento do faturamento da empresa, mas à combinação de preço e ao volume mais lucrativo (Sperling, 2008). O preço de venda 
deve ser justo para o consumidor e adequado para garantir a manutenção e desenvolvimento da empresa.

As microempresas têm grandiosa representatividade no Brasil, por isso a relevância de serem estudadas. Segundo dados do portal Data SEBRAE (2016), o número de microempresas (MEs) no Brasil passou de 2,9 milhões, em 2010, para 3,4 milhões, em 2013, representando um crescimento de $12,25 \%$ no período. Entre esse mesmo período (2010-2013) o percentual de crescimento das microempresas representou $29,66 \%$ do crescimento total de empresas existentes no país.

Inserido no contexto no qual a gestão da informação empresarial é um requisito essencial para abertura, manutenção e expansão de um negócio, este estudo objetivou aplicar e analisar ferramentas gerenciais e suas utilidades em uma microempresa varejista do ramo de confecções. Sendo assim, a seguinte pergunta nortou este trabalho: Como as ferramentas gerenciais podem auxiliar na gestão empresarial de uma microempresa?

Com a aplicação do modelo Canvas de negócio como forma de diagnóstico, foi possível constatar que a empresa necessitava de direcionamento e informações precisas na área financeira. A falta de organização e planejamento acabou gerando endividamento em um montante desnecessário, dívidas essas realizadas para financiar a compra de mercadorias e estruturação da loja.

Este estudo caracteriza-se por um relatório técnico-científico e será organizado em seis capítulos: introdução, fundamentação teórica, metodologia, diagnóstico, resultados e considerações finais.

\section{FUNDAMENTAÇÃO TEÓRICA}

\subsection{Modelo Canvas de Negócios}

De acordo com Osterwalder e Pigneur (2011), um modelo de negócio é a descrição do valor que a companhia oferece a um ou mais segmentos de clientes. De forma sucinta, consiste na forma como a empresa cria, faz marketing e entrega esse valor através do capital de relacionamento, para que um ou vários segmentos de clientes possam gerar fontes de receita rentáveis e sustentáveis.

Com o Business Model Canvas (BMC), pode-se descrever com facilidade um modelo de negócios, mas para isso é preciso aprender como desenvolvê-lo. De acordo com o Sebrae (2013), o ideal é construir o modelo em uma folha de bom tamanho e completá-la com a participação dos sócios ou da equipe de desenvolvimento. Para o preenchimento desse modelo de negócio é possível utilizar blocos de papéis tipo post-it, 
preenchê-los, colocando-os em cada bloco, para não haver a perda das ideias que forem surgindo pelo grupo. Todos os espaços disponibilizados pelo Modelo Canvas de Negócios são de essencial importância. No total, são nove espaços a serem preenchidos, com as seguintes informações (Osterwalder, \& Pigneur, 2011):

a) Segmentos de clientes: nesse bloco, devem ser descritos os diferentes tipos de clientes para quem as ofertas se dirigem;

b) Proposta de valor: a oferta é o que atrai os clientes, pode ser entregue ao cliente como um pacote de produtos, serviços, procurando destacar seus principais atributos que podem se tornar um diferencial aos demais da concorrência;

c) Canais de distribuição: a questão fundamental nesse bloco é identificar quais os canais ou meios serão necessários para se acessar os clientes, que formas serão precisas para se comunicar com eles e para lhes entregar a proposta de valor ofertada;

d) Relacionamento com os clientes: nesse ponto, deve-se determinar que tipos de relações deve-se utilizar para cada um dos segmentos atendidos;

e) Fluxo de receitas: são os rendimentos recebidos pela proposição de valor ofertado;

f) Recursos-chave: são os recursos essenciais para que uma empresa ou qualquer negócio funcione. Pode ser o espaço físico, maquinário, recursos humanos e financeiros;

g) Atividades chaves: representam as principais atividades e processos a serem realizadas pelo empreendimento para produzir a oferta de valor, manter os relacionamentos com clientes e parceiros-chave;

h) Parceiros-chave: deve ser composta pelos aliados e fornecedores que possam vir a contribuir nas atividades;

i) Estrutura de custos: aqui devem ser descritos todos os valores desembolsados que são (ou serão) necessários para o funcionamento da atividade produtiva.

Diante disso, pode-se observar que o Modelo Canvas de Negócios é uma ferramenta altamente visual, prática e dinâmica, que possui o poder de fazer com que o empresário pense em seu negócio, desde sua criação até uma possível reformulação de seus objetivos, definindo claramente sua proposta de valor e criando estratégias mais acertivas baseadas nos demais elementos do modelo.

\subsection{Formação de Preço de Venda}

A fixação de preço de venda dos produtos é uma questão delicada no que tange à vida de uma empresa, independentemente do seu porte, atividade ou setor econômico 
de atuação e deve ter como finalidade primordial o auxílio ao gestor no momento de determinação de um preço específico, como também estabelecer as políticas e estratégias de preços (Santos, 1995).

Santos (1997) salienta ainda que a política de formação do preço de venda dos produtos e serviços proporciona à empresa uma estratégia de grande relevância, além de garantir bons resultados e, consequentemente, a continuidade da empresa em longo prazo. A partir desses fatores, são utilizados três principais processos para a formação de preço de venda do produto ou serviço orientado: no cliente, na concorrência e nos custos (Bruni, \& Famá, 2009).

O procedimento de formação de preços orientado pelos clientes é baseado no valor percebido do produto ou serviço pelo consumidor e não nos custos que o vendedor ou prestador de serviço incorrem ao colocar o produto ou serviço à disposição do cliente (Kotler, \& Armstrong, 2007).

Segundo Bruni e Famá (2009) os preços definidos pela concorrência podem ser de "oferta ou de proposta". Os preços de oferta consistem no fato de a empresa cobrar acima ou abaixo dos preços praticados pela concorrência e os preços de proposta ocorrem quando a empresa fixa seu preço a partir de um julgamento de como os concorrentes fixarão seu preço.

Por fim, na opinião de Assef (2005): "formar preço pelo custo implica repassar ao cliente seus custos de produção, distribuição e comercialização, além das margens propostas para o produto".

Para se calcular o preço de venda, existem ferramentas como o Mark-up, que é a taxa de marcação, ou seja, um índice utilizado para que se alcance o preço de venda dos produtos. Essa ferramenta foi escolhida para a empresa em estudo, pois tem alta precisão, além de ser facilmente calculada.

Segundo Wernke (2005), existem duas formas de calcular o Mark-up, que seria o Mark-up Divisor e Mark-up Multiplicador, nos quais, independentemente de qual tipo seja utilizado, o valor do preço de venda a ser praticado será igual nas duas formas, o que muda somente é a forma de calcular e o percentual dos índices.

Diante dessas observações, pode-se, de forma resumida, apresentar as fases de cálculo do Mark-up divisor e multiplicador na Figura 1: 
Aplicação de Ferramentas de Apoio Gerencial Contábil em uma Microempresa de Confecções

\begin{tabular}{|c|c|}
\hline Mark-up divisor & Mark-up multiplicador \\
\hline $\begin{array}{l}\text { a) listar todos os percentuais incidentes sobre o preço } \\
\text { de venda (\% PV): } \\
\text { Tributos incidentes sobre vendas = } 17 \% \\
\text { Comissões sobre vendas }=3 \% \\
\text { Lucro almejado }=5 \%\end{array}$ & $\begin{array}{l}\text { a) listar todos os percentuais incidentes sobre o } \\
\text { preço de venda (\% PV): } \\
\text { Tributos incidentes sobre vendas = } 17 \% \\
\text { Comissões sobre vendas }=3 \% \\
\text { Lucro almejado }=5 \%\end{array}$ \\
\hline $\begin{array}{l}\text { b) somar todos os percentuais incidentes sobre o } \\
\text { preço de venda }(\%) \text { : } \\
(17 \%+3 \%+5 \%=25 \%)\end{array}$ & $\begin{array}{l}\text { b) somar todos os percentuais incidentes sobre o } \\
\text { preço de venda }(\%) \text { : } \\
(17 \%+3 \%+5 \%=25 \%)\end{array}$ \\
\hline $\begin{array}{l}\text { c) dividir a soma dos percentuais sobre o preço de } \\
\text { venda }(\% \mathrm{PV}) \text { por "100" (para achar a forma } \\
\text { unitária): } \\
(25: 100=0,250000)\end{array}$ & $\begin{array}{l}\text { c) partindo de "100\%", subtrair a soma dos } \\
\text { percentuais sobre o preço de venda }(\% \mathrm{PV}) \text { : } \\
(100 \%-25 \%=75 \%)\end{array}$ \\
\hline $\begin{array}{l}\text { d) subtrair de "1" o quociente da divisão da fase } \\
\text { anterior (c): } \\
(1-0,250000=0,750000)\end{array}$ & $\begin{array}{l}\text { d) o Mark-up multiplicador é obtido dividindo } \\
\text { "100" pelo resultado da fase anterior (c): (100: } \\
75=1,333333)\end{array}$ \\
\hline $\begin{array}{l}\text { e) dividir o Custo da Compra da mercadoria (no } \\
\text { caso do comércio) ou o Custo unitário Total (no } \\
\text { âmbito industrial) pelo Mark-up divisor, apurando } \\
\text { o preço de venda orientativo: Supondo que o } \\
\text { custo unitário da mercadoria seja de } \$ 500 \text {, o } \\
\text { preço de venda à vista seria, então, de } \\
\$ 666,67(\text { pois } \$ 500 / 0,750000=\$ 666,67) \text {. }\end{array}$ & $\begin{array}{l}\text { e) o preço de venda orientativo é calculado } \\
\text { multiplicando o custo unitário pelo Mark-up } \\
\text { multiplicador, admitindo que o custo unitário } \\
\text { seja de } \$ 500 \text {, ao multiplicar tal valor por } \\
1,33333 \text { (resultante da fase "d") obtém-se o } \\
\text { preço de venda de } \$ 666,67 \text {. }\end{array}$ \\
\hline
\end{tabular}

Figura 1: Fases de cálculo do Mark-up

Fonte: Adaptado de Wernke (2005)

Essas ferramentas disponibilizam informações suficientes para análises que objetivem a redução de custos, políticas de incremento de vendas ou redução dos preços unitários de venda, assim, pode-se chegar ao valor correto a se atribuir às mercadorias que serão vendidas.

\subsection{Fluxo de Caixa}

Para Assaf Neto (2007), o fluxo de caixa é um mecanismo elaborado para estabelecer uma relação entre as receitas e despesas de uma empresa em determinado período, com o propósito de detectar possíveis faltas ou excedentes de caixa, determinando assim as próximas ações do gestor financeiro quanto aos resultados obtidos. Possibilita também prever se haverá necessidade de se buscar recursos para sanar as contas ou fazer investimentos dos excedentes.

Segundo Leal e Nascimento (2011), o fluxo de caixa possibilita o controle das receitas e despesas. É realizado pela relação de todas as entradas e saídas financeiras, de forma que se verifique lucros ou prejuízos da organização. Dessa forma, a empresa mostrará que possui controle de suas receitas e despesas.

Rosa e Silva (2011) definem que o fluxo de caixa realizado tem a finalidade de mostrar como se comportaram as entradas e saídas de recursos financeiros da empresa 
em um período específico. Ainda segundo os autores, ele serve de base para a elaboração do fluxo de caixa projetado.

Existem vários métodos de previsão de demanda, entretanto, Oliveira (2005) sugere o mais simples de todos, que é se pautar nas vendas ocorridas no mesmo período do ano anterior, acrescendo este valor com a projeção de crescimento esperado para as vendas da empresa.

Tófoli (2008) afirma que o Fluxo de Caixa gerencial tem a função de agenda, registrando os recebimentos e pagamentos de um período. Sendo assim, torna-se imprescindível que o administrador financeiro tenha esse controle para saber quando haverá caixa disponível para os vencimentos da organização.

\section{METODOLOGIA}

Quanto aos objetivos, o estudo foi definido como exploratório. Andrade (2002) ressalta algumas finalidades primordiais desse tipo de pesquisa, tais como: proporcionar maiores informações sobre o assunto que se vai investigar; facilitar a delimitação do tema de pesquisa; orientar a fixação dos objetivos e a formulação das hipóteses; ou descobrir um novo tipo de enfoque sobre o assunto.

Em relação aos procedimentos, classifica-se como um estudo de caso. Segundo Yin (2005, p. 32): "o estudo de caso é uma investigação empírica de um fenômeno contemporâneo dentro de um contexto da vida real, sendo que os limites entre o fenômeno e o contexto não estão claramente definido".

Quanto à abordagem, o estudo empregou a qualitativa, pois Giovinazzo (2001) relata que a pesquisa qualitativa é útil para firmar conceitos e objetivos a serem alcançados e dar sugestões sobre variáveis a serem estudadas com maior profundidade.

Como procedimento de análise, foi realizado o cruzamento da visão teórica dos autores e dos instrumentos elaborados durante o estudo com os dados extraídos na empresa observada, permitindo assim, ao pesquisador, identificar os melhores parâmetros empregados na elaboração das ferramentas e dados gerenciais relevantes gerados no processo, os quais foram base para os comentários gerenciais e as conclusões do estudo.

Creswell (1998), Stake (1995) e Eisenhardt (1989) definem que a verificação aplicada ao estudo de caso se refere basicamente à triangulação dos dados, buscando a convergência das informações. Essa atitude está de acordo com a validade de construto comentada por Yin (2005). 
Para a análise do diagnóstico da empresa em questão, foram utilizadas as perspectivas do Modelo Canvas de Negócios, o qual vislumbra a proposta de valor da empresa e faz com que seus gestores possam repensar na forma de atuação no mercado.

\section{CONTEXTO DA SITUAÇÃO-PROBLEMA}

A empresa em estudo foi constituída em 1991, mas sua principal atividade (comércio) foi iniciada apenas em 2006, até então, a empresa trabalhava apenas com a fabricação de blusas modelo cacharréis femininas, uma espécie de blusa de lã, tecida por máquinas. A empresa está localizada na região oeste do Paraná e não conta com nenhum colaborador, apenas os dois sócios que fazem o trabalho administrativo e de vendas. Os sócios possuem ensino médio completo, um deles possui ampla experiência com vendas, é responsável pela gestão financeira e administrativa da entidade e a outra sócia é a vendedora. Os principais produtos da organização são as confecções, em maior volume femininos, dentre eles: blusas, calças, saias, vestidos, camisetas e shorts, dos mais variados tecidos, dentre eles: jeans, algodão e viscose.

A empresa está enquadrada no Simples Nacional e foi constituída como sociedade limitada. A organização atualmente comercializa o seu produto apenas no varejo e o maior volume de vendas são mercadorias adquiridas de terceiros.

No que diz respeito à concorrência, em sua região há em torno 4 concorrentes diretos que têm maior influência na opção de compras dos clientes em potencial. Porém, as lojas localizadas no centro da cidade também são consideradas concorrentes, pois geralmente possuem poder de compra maior e por esse motivo seus preços são mais baixos, o que acaba atraindo os moradores do bairro.

Os fornecedores são $90 \%$ da cidade de São Paulo e a sócia vendedora realiza viagens durante o mês para realizar as compras de mercadorias. Peças de menor valor ou não encontradas nas viagens são compradas de representantes comerciais e atacados localizados em Cascavel. Os clientes estão localizados no próprio bairro e regiões próximas, sendo que, embora haja mercadorias voltadas ao público masculino, quase a totalidade das vendas é realizada para mulheres de classe média.

Sob a perspectiva da proposta de valor, pode-se entender que a empresa possui deficiência, pois não conseguiu definir qual é sua estratégia, se menor custo, para fazer frente com os seus concorrentes, ou por diferenciação, não importando o preço e sim que seus produtos sejam diferenciados e únicos. A ferramenta gerencial de formação de preço de venda, nesse caso, demonstra-se passível de aplicação, pois permite aos 
empresários conhecer o quanto precisam vender para atingir determinado resultado ou o ponto de equilíbrio. Trata-se de uma ferramenta útil para saber o quanto precisam faturar para cobrir seus principais gastos e fidelizar a clientela com valores competitivos. Além disso, os gestores possuem dificuldades em constatarem se a empresa está obtendo lucro e têm dificuldade de vender estoques obsoletos.

No que tange aos segmentos de clientes, a empresa tem dificuldade em definir com precisão qual é seu público alvo, não possui qualquer estatística apurada sobre isso, o que dificulta a questão do marketing, uma vez que as ferramentas de divulgação também são muito importantes no que se refere à imagem da organização, pois sem elas a empresa fica sem identidade e não é lembrada pelo seu nome, não tendo assim, influência em sua praça.

No que diz respeito ao relacionamento com os clientes, deve-se reforçar a utilização das mídias sociais, pouco exploradas pela empresa, mas que oferecem uma grande oportunidade de expansão da marca, além de melhor atender os clientes, que atualmente estão muito próximos às tecnologias, facilitando assim seu alcance.

Do ponto da estrutura de custos e do fluxo de receitas, pode-se avaliar que a organização possui poucos controles, principalmente aqueles que possam acompanhar sua evolução em termos de faturamento, mensuração de resultados, análise das demonstrações e outros controles gerenciais que possam demonstrar sua situação financeira e patrimonial.

Em relação aos parceiros-chave, como o processo de compra se dá por meio de viagens a centros de compras atacadistas, a organização não tem um orçamento para compra de seus produtos para revenda.

Uma das dificuldades é a falta de parcerias com fornecedores, o que dificulta a cobrança por qualidade dos produtos, enfraquece o poder de barganha e ainda deixa a empresa sem outras opções no mercado, quando um ou outro fornecedor deixa de existir ou simplesmente não possui mais certo produto, além de não poder atender de forma imediata em casos de urgência de reposição de estoque.

Algo que é ausente nos canais de distribuição da organização é o controle de estoque, pois não há informações sobre estoque mínimo, estoque de segurança, quais são os produtos "carro-chefe", ou seja, aqueles que vendem mais ou possuem maior margem líquida de venda. Como o pagamento das compras é realizado à vista e a empresa não possui um planejamento de fluxo de caixa para a realização dessas compras, é necessária a busca de financiamentos bancários para a aquisição das mercadorias. 
Em relação ao recebimento das vendas, outro ponto a melhorar da empresa, é necessário maior controle no que diz respeito ao crediário, pois a empresa não possui um sistema de geração de boletos e inclusão de devedores em processos de cobrança, o que acaba por tornar a cobrança impossível, e a perca por inadimplência elevada. Mesmo aqueles que pagam, muitas vezes não o fazem na data correta para pagamento e mesmo se fizessem, a empresa não possui um fluxo de caixa elaborado, ferramenta pela qual poderia planejar de melhor forma seus recebimentos para garantir o capital de giro.

As demonstrações contábeis são elaboradas por um escritório de contabilidade, que não elabora nenhum instrumento financeiro para acompanhamento da empresa. Diante disso, sugere-se a implantação da ferramenta de Fluxo de caixa realizado e projetado para análise diária do caixa e da capacidade de pagamento e recebimento em longo prazo.

Ao analisar a empresa em seu processo operacional, é possível constatar que não há qualquer tipo de gestão estratégica da organização, não há definição de visão ou valores e não são usados relatórios gerenciais para a tomada de decisão, o que também se deve à falta de dados para gerar informações concisas e fidedignas que demonstrem a realidade e possibilitem aos gerentes, tomarem as decisões. Desse ponto de vista, a ferramenta do Modelo Canvas de Negócios foi ideal para definir a aplicação de ações essenciais para a continuidade da organização e fazer os gestores pensarem seu modelo de negócio.

Sendo assim, acredita-se que existem três ferramentas básicas que podem nortear o futuro da empresa e auxiliar na gestão do negócio. A primeira, é o Modelo Canvas de Negócios, desenvolvido por Osterwalder e Pigneur (2011), que conta com nove dimensões que cobrem os três pilares conceituais da definição de modelo de negócios: criação de valor (parcerias-chave, atividades-chave e recursos-chave); entrega de valor (canais, segmento de clientes e relacionamentos com o cliente); e captura de valor (estrutura de custo e fontes de receitas). A segunda, é a Formação de Preço de Venda, pois não é possível atingir metas de vendas e lucratividade, sem saber quanto custa e por qual preço pode-se vender os produtos. E por fim, a ferramenta de Fluxo de Caixa permitirá que a empresa conheça qual a melhor alocação dos recursos financeiros e planeje de melhor forma seus orçamentos de compras e receitas, além de poder visualizar se a empresa é lucrativa em longo prazo, ou se a possibilidade de alocar o montante do negócio em outros investimentos é mais viável.

\section{RESULTADOS}

Revista de Empreendedorismo e Gestão de Pequenas Empresas | v.8 | n.1 | p. 201-218 | Jan/Abr. 2019. 
Durante a aplicação do Modelo Canvas de Negócios, pode-se constatar que a empresa em questão passa por algumas dificuldades financeiras devido à falta de planejamento, principalmente de seus objetivos, finanças e imagem corporativa. A ferramenta Canvas nada mais é do que um artifício para que os sócios repensem no negócio e planejem qual será o rumo que a organização tomará.

Com a aplicação do Canvas foi possível elaborar algumas propostas de intervenção, a fim de corrigir os problemas encontrados e maximizar a utilização de controles na organização, como apresentado na Figura 2:

\section{$1^{\text {a }}$ - Expansão de clientes por segmento}

Como a organização tem a meta de atingir apenas a população do bairro, mas tem a necessidade de expandir o número de clientes, ficou evidente a necessidade de definir através de métricas exatas, o número de clientes por segmento e promover, através do marketing, formas de atingir com mais eficiência os públicos-alvo.

\section{$2^{\text {a }}$ - Melhorar o sistema de controle de mercadorias em condicional}

A organização utilizava de anotações em cadernos para controlar mercadorias em condicional, mas definiu-se a necessidade de adoção de um sistema para controle, o qual pode ser facilmente realizado através do sistema de informática que a empresa possui.

\section{3 - Expor a imagem corporativa nas redes sociais}

Serão criadas páginas em redes sociais para propagação da imagem corporativa e do valor que ela oferece, através de meios gratuitos, como Facebook e Whatsapp.

$4^{\mathrm{a}}$ - Criar formulários de avaliação pelos clientes4 - Criar formulários de avaliação pelos clientes

Será implantado um processo de avaliação da organização pelos clientes, apontando seus pontos fortes e a

melhorar, através de formulários que serão preenchidos por eles após o atendimento.

\section{5a - Renovar frequentemente os estoques}

Como foi identificado que a empresa tem picos de vendas nos momentos em que renova seus estoques, foi definido que os estoques serão renovados constantemente (espaço de tempo de no máximo 2 semanas e não 2 meses como era feito).

\section{6a - Cadastrar clientes}

Ficou clara a necessidade de um controle de cadastro de clientes, através do qual, será possível entrar em contato com os compradores e verificar suas necessidades e aproximar a relação entre cliente e empresa.

\section{$7^{\mathrm{a}}$ - Elaborar ferramenta de formação de preço de venda}

Torna-se necessário a implantação da ferramenta de formação de preço de venda, pois a organização não sabe para quem está vendendo mais, qual é o segmento que lhe dá maior margem de contribuição, quais são os produtos "carro-chefe" e o valor adequado de venda de seus produtos, para que estes possam refletir os resultados esperados pela empresa.

\section{$8^{\text {a }}$ - Executar mudanças nas formas de recebimento}

Constatou-se a necessidade de mudança na forma de recebimento das vendas, no que diz respeito ao crediário, pois foi identificado um alto índice de inadimplência e, por isso, será implantado o sistema de cobrança por boleto, o que possibilita a cobrança extrajudicial pelo não pagamento. Além disso, a empresa terá uma política de descontos nas compras em dinheiro ou cartão, pois no cartão há a possibilidade de parcelamento das vendas e a certeza de recebimento, buscando diminuir as perdas.

\section{9 - Realizar manutenção das estruturas}

Será comprado um ar-condicionado, para garantir maior conforto para os clientes provarem os produtos e a fachada da loja será pintada, para deixar visível as pessoas a preocupação com a imagem da organização.

\section{0a - Abolir financiamentos bancários}

Os sócios comprometeram-se a não realizarem mais financiamentos bancários para captação de

Revista de Empreendedorismo e Gestão de Pequenas Empresas | v.8 | n.1 | p. 201-218 | Jan/Abr. 2019. 
dinheiro após quitarem todas as dívidas. Passarão, portanto, a planejar outras formas de obtenção de dinheiro e aplicação.

\section{$11^{\text {a }}$ - Desenvolver habilidades técnicas}

Foi proposto aos sócios, a inserção em cursos de técnicas de vendas, atualização do mercado da moda e também, cursos de gestão.

\section{2. - Realizar eventos com os clientes}

Uma atividade importante, que será implantada, é a realização de eventos para atrair clientes, como cafés coloniais e outras formas de se aproximar com os clientes, criando um vínculo com eles e garantindo sua fidelização.

\section{$13^{\mathrm{a}}$ - Realizar promoções}

Deve-se criar promoções em datas comemorativas, pois foi observado, através da entrevista, que não é realizado esse tipo de promoção, que é fortemente recomendada para atrair novos clientes. Além disso, também serão criadas promoções de vendas esporádicas e sistemas de recompensas, como "compre 3 e pague 2', etc.

\section{$14^{\mathrm{a}}$ - Utilizar software gerencial}

A loja possui um sistema gerencial, porém este não é utilizado, por falta de conhecimento técnico dos sócios e funcionário. Será realizado, portanto, treinamentos com profissionais qualificados para utilização do software com máxima eficiência e utilização de seus módulos.

\section{5a - Fechar parcerias com fornecedores}

Os sócios buscarão o fechamento de parcerias com fornecedores da cidade de São Paulo, afim de que estes enviem mercadorias por Correio/Sedex, garantindo um valor menor gasto com logística, além da constante atualização dos estoques e possibilidade de negociação de melhores prazos.

\section{6a - Planejar o fluxo de caixa}

A empresa passará a utilizar a ferramenta de fluxo de caixa para melhor planejar seus recebimentos e pagamentos, afim de estender os prazos de pagamento e encurtar os recebimentos.

\section{$17^{\mathrm{a}}-$ Reduzir custos}

Serão avaliadas outras alternativas em relação à cidade de São Paulo, já que outros polos de compras mais pertos ou que tenham um custo menor de deslocamento podem garantir também as exigências do valor que a empresa quer transmitir a seus clientes.

\section{Figura 2: Ações propostas para intervenção}

Fonte: 0 Autor (2017)

Dentro do que foi proposto, a organização não precisará de uma grande saída de caixa para realizar tais ações, mas sim, um melhor planejamento para correta utilização de suas ferramentas e recursos disponíveis.

A ferramenta Canvas, possibilitou que a empresa vislumbrasse o que estava fora de ordem em seu fluxo operacional e a partir dessa visão, será possível a manutenção constante dos nove blocos, pois foram necessárias habilidades críticas elevadas, já que se tratou de uma ferramenta que faz parte do planejamento estratégico da organização e busca definir, por meio de pontos específicos, quais são os objetivos e onde a empresa está atuando. A utilização da ferramenta de Formação de Preço de Venda contribuiu significativamente para o negócio. Pôde-se perceber os pontos críticos que contribuem para o pequeno crescimento da organização e as oportunidades de melhoria, tanto nos custos dos produtos, quanto em seu valor final de venda, quantidade e demais aspectos que possuem relação direta com o lucro da empresa.

$\mathrm{Na}$ aplicação dessa ferramenta, foi realizado um levantamento de todo o estoque da loja (inventário), destacando as quantidades, valores unitários de custo de aquisição das mercadorias e as características peculiares de cada produto, como marca, tamanho e 
gênero. O proprietário, possui um relatório das vendas mensais, o que foi muito útil para o cálculo da média das vendas de 2017. Também passou a fazer um relatório de despesas mensais (3 meses), que serviu de base para cálculo da média das despesas da empresa. Além disso, foi elaborado uma Demonstração do Resultado do Exercício (DRE) referente aos dias primeiro à 31 de agosto de 2017.

$\mathrm{Na}$ DRE, pôde-se constatar que o custo das mercadorias vendidas, representam cerca de $60 \%$ das receitas, o que é um índice considerado alto. Além disso, as despesas operacionais representam cerca de $40 \%$ das receitas. Sendo assim, foi constatado no mês de agosto um prejuízo no valor de $\mathrm{R} \$ 349,12$. Sugere-se, portanto, que a empresa foque em aumentar as suas receitas, já que as despesas operacionais e os custos das mercadorias vendidas não são valores absurdos, além de serem difíceis de diminuição, já que são valores essenciais para a continuidade das atividades da empresa. Contudo, em comparação com a baixa receita, acaba por representar um alto valor.

Percebeu-se a possibilidade de aumentar o valor de venda de alguns produtos, enquanto outros, há a possibilidade de diminuir o valor, com base no cálculo do Mark-up (divisor e multiplicador). Para o estudo, foram realizados os dois tipos de Mark-up, os quais não possuem diferença em seu valor final, apenas na forma de se calcular. Sendo assim, a variação média entre o valor praticado e o encontrado através do Mark-up foi de $18,37 \%$ para maior, ou seja, a empresa deve adotar esse percentual para aumento do valor médio dos preços praticados.

Através dessa ferramenta, foi possível identificar que a empresa em questão formava seus preços sem qualquer métrica considerada segura e real e que a falta dessas informações impossibilitou o desenvolvimento de programas de promoções e o conhecimento efetivo do resultado obtido de suas vendas. A partir da implementação da ferramenta de Formação de Preço de Venda, será possível planejar melhor as compras de mercadorias, os custos e elaborar melhores preços para alcançar os resultados buscados.

Diante da aplicação da ferramenta de Fluxo de Caixa, foram observados detalhes que demonstram que a saúde financeira da organização passa por dificuldades, pois foram constatados saldos negativos no Fluxo de Caixa em praticamente todos os meses.

$\mathrm{Na}$ Figura 3 a seguir, pode-se perceber que as saídas de caixa estão sempre maiores do que as entradas: 
Aplicação de Ferramentas de Apoio Gerencial Contábil em uma Microempresa de Confecções

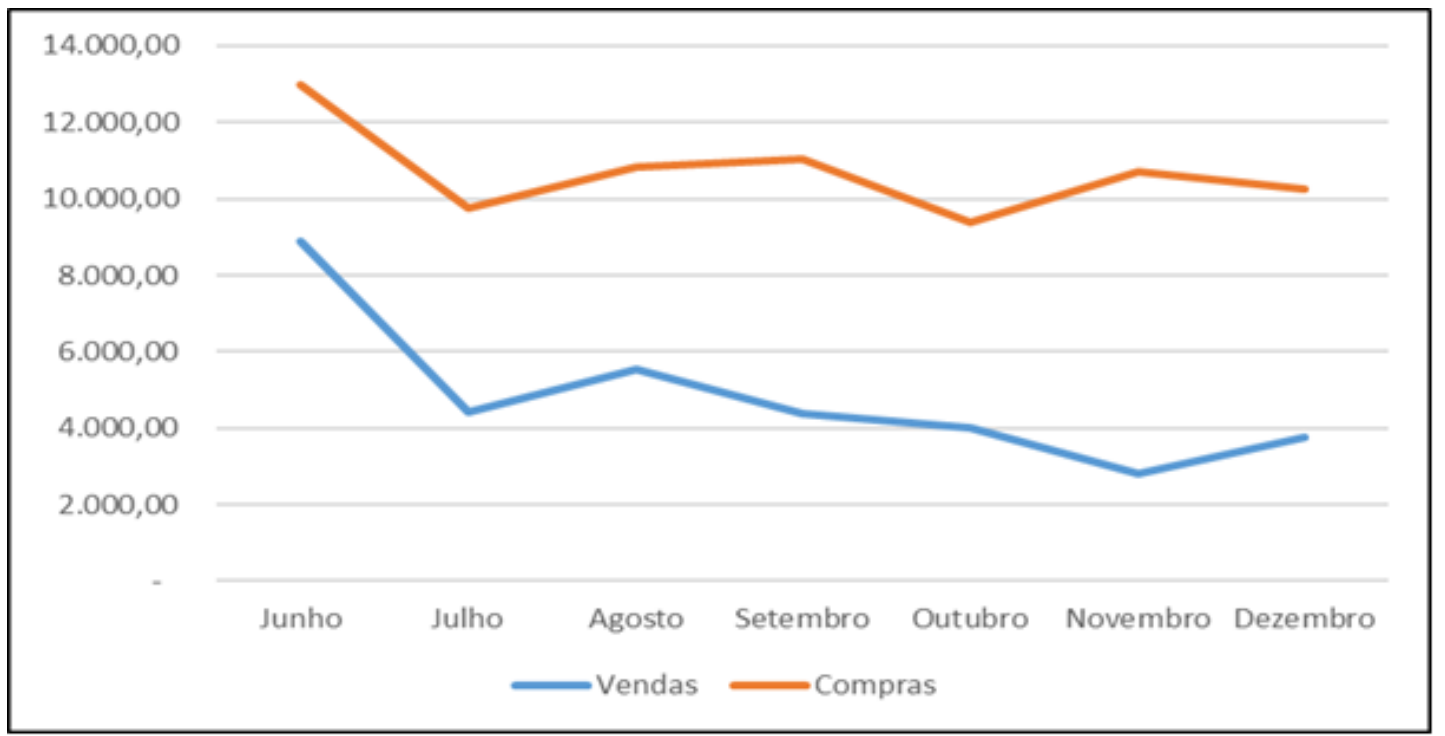

Figura 3: Fluxo de caixa

Fonte: 0 autor (2017)

Pode-se notar que o valores médios das saídas de caixa giram em torno de $R \$$ $10.000,00$, porém as entradas, em $\mathrm{R} \$ 5.000,00$. Um fator que acentua essa diferença é a quantidade de financiamentos pagos pela empresa, o que representa em torno de $30 \%$ da média mensal com despesas. Esses financiamentos, foram realizados para ampliação do negócio e compra de mercadorias para revenda, porém, os resultados esperados, que seriam principalmente o aumento das vendas, não aconteceram como o previsto.

Em relação ao fluxo de pagamentos e recebimentos diários, pode-se notar que os recebimentos e vendas à vista, estão distribuídos de forma bastante heterogênea até o vigésimo dia do mês, e que nos últimos dias há uma leve queda nas entradas de caixa. As contas, porém, são pagas em sua maior parte, até o dia 20 do mês também. Porém, para que o caixa não fique negativo em algumas datas, seria interessante acumular os valores em caixa recebidos no início e metade do mês e realizar a maior parte dos pagamentos após o dia 20. Por fim, a Demonstração do Resultado do Exercício, a qual foi elaborada na ferramenta anterior, não demonstra de fato a condição financeira da empresa, pois ela reflete a condição econômica, além de trabalhar sob o regime de competência. Com isso, contata-se que, mesmo possuindo um prejuízo contábil de $\mathrm{R} \$ 349,12$ no mês de agosto, o seu prejuízo de caixa foi de $\mathrm{R} \$ 5.784,01$, revelando assim a baixa rentabilidade da organização.

\section{CONSIDERAÇÕES FINAIS}

O objetivo deste trabalho foi identificar como as ferramentas podem auxiliar na gestão empresarial de uma microempresa, sendo para isso implantadas três ferramentas de gestão em uma empresa familiar do ramo de comércio de confecções. 
Em uma análise inicial, pôde-se constatar que a empresa em questão não possuía nenhum tipo de controle, apenas vagos registros, os quais serviram, mesmo que de forma incompleta em grau de informações, de auxílio para a implantação das três ferramentas propostas.

A ferramenta Canvas possibilitou que a empresa vislumbrasse o que estava fora de ordem em seu fluxo operacional e a partir dessa visão, será possível a manutenção constante dos nove blocos, pois foram necessárias habilidades críticas elevadas, já que se tratou de uma ferramenta que faz parte do planejamento estratégico da organização e busca definir, por meio de pontos específicos, quais são os objetivos e onde a empresa está atuando.

A partir da implementação da ferramenta de Formação de Preço de Venda, foi possível planejar melhor as compras de mercadorias e os custos, entendendo-se que os métodos para calcular o preço de venda dos produtos garantem os resultados almejados. Também elaborar estratégias de vendas que incentivem os clientes à compra de produtos mais lucrativos para a empresa e promoções quanto aos produtos que necessitam de maior volume de vendas para garantir uma boa rentabilidade.

Já a utilização do Fluxo de Caixa foi pertinente, pois pôde-se perceber a diferença entre o lucro contábil, apurado pela Demonstração do Resultado do Exercício, o lucro financeiro, que é o que de fato os empresários buscam, e a geração de caixa futuro. Assim, é possível discernir entre as melhores providências a serem tomadas pelos sócios para buscarem alternativas e maximizarem o saldo positivo de caixa.

Diante disso, pôde-se verificar que as ferramentas selecionadas auxiliam os gestores da organização em questão, no sentido de que demonstraram a eles que a forma como está sendo gerenciado o negócio atualmente é inviável. Sugere-se à empresa, portanto, a adoção de políticas de incremento de vendas e o aumento do valor médio de preço de seus produtos, em decorrência do que foi demonstrado com a utilização da ferramenta de formação de preço de venda. Além disso, aconselha-se a reprogramação do Fluxo de Caixa, planejando de forma mais adequada os pagamentos.

Nesse sentido, sugere-se a busca por redução do capital de terceiros na empresa estudada, pois como foi visualizado, boa parte do caixa está comprometido com o pagamento de empréstimos e financiamentos. Os sócios acataram todas as orientações e afirmaram que utilizarão as ferramentas gerenciais para acompanharem melhor os resultados da organização. Por fim, novos estudos podem ser realizados para que possam comparar outros possíveis investimentos ou áreas de negócio para a organização estudada nesta pesquisa, pois a empresa possuía o ramo industrial até certo tempo atrás, mas parou 
de fabricar por questões não especificadas pelos sócios, e este poderia ser um empreendimento viável. Sugere-se ainda o acompanhamento após a implantação dessas ferramentas, para constatar se a empresa está utilizando de fato as ferramentas, de forma correta e se essas estão lhe trazendo os resultados esperados.

\section{REFERÊNCIAS}

Andrade, M. M. (2002). Como preparar trabalhos para cursos de pós-graduação: noções práticas. 5. ed. São Paulo: Atlas.

Assaf Neto, A. (2007). Finanças corporativas e valor. 3. ed. São Paulo: Atlas.

Assef, R. (2005). Manual de gerência de preços: do valor percebido pelo consumidor aos lucros da empresa. Rio de Janeiro: Campus.

Bruni, A. L., \& Famá, R. (2009). Gestão de custo e formação de preço: com aplicação na calculadora HP12C e Excel. 6. ed. São Paulo: Atlas.

Crepaldi, S. A. (1998). Contabilidade gerencial, teoria e prática. São Paulo: Atlas.

Creswell, J. W. (1998). Qualitative inquiry and research design: choosing among five traditions. Thousand Oaks, CA: Sage.

Eisenhardt, K. M. (1989). Building theories from case study research. Academy of Management Review, Mississipi, Mass., v. 14(4), pp. 532-550, Oct./Dec.

Frezatti, F. (2005). Management accounting profile of firms located in Brazil: a field study. Brazilian Administration Review, v. 2(1), pp. 73-87, Jan/Jun.

Giovinazzo, R. A. (2001). Focus Group em pesquisa qualitativa. Artigo, Fundação Escola de Comércio Álvares Penteado (FECAP). Disponível em: <http://www.fecap.br/>. Acesso em: 16 jun. 2017.

Kotler, P., \& Armstrong, G. (2007). Princípios de Marketing. 12. ed. São Paulo: Prentice Hall Brasil.

Leal, C. P., \& Nascimento, J. A. R. (2011). Planejamento Financeiro Pessoal. Disponível em:

<http://www.pgsskroton.com.br/seer/index.php/rcger/article/view/2101/3439>. Acesso em: 05 nov. 2017.

Nagatsuka, D. A. S., \& Teles, E. L. (2002). Manual de contabilidade introdutória. São Paulo: Thompson/Pioneira.

Oliveira, E. C. (2005). Manual Como Elaborar Controles Financeiros. Disponível em: <http://www.sebrae.com.br/uf/ceara/acesse/publicacoes-1/planeje-suasacoes/Plano Financeiro.pdf>. Acesso em: 20 out. 2017. Belo Horizonte: SEBRAE/MG.

Osterwalder, A., \& Pigneur, Y. (2011). Business Model Generation. New Jersey: John Wiley \& Sons Inc.

Rosa, P. M., \& Silva, A. T. (2011). Fluxo de caixa - instrumento de planejamento e controle financeiro e base de apoio ao processo decisório. Revista Brasileira de 
Contabilidade, [S.I.], n. 135, pp. 81-95, ago. ISSN 2526-8414. Disponível em: <http://rbc.cfc.org.br/index.php/rbc/article/view/425>. Acesso em: 19 jul. 2017.

Santos, R. V. (1997). Planejamento do Preço de Venda. Caderno de Estudos FIPECAFI, São Paulo. v. 9(15), pp. 60-74, jan/ jun.

(1995). Modelos de decisão para gestão de preço de venda. São Paulo: USP, 1995. Dissertação (Mestrado) - Faculdade de Economia, Administração e Contabilidade, Universidade de São Paulo, São Paulo.

SEBRAE. (2016). São Paulo, Serviço Brasileiro de apoio às Micro e Pequenas Empresas. Dados sobre os pequenos negócios no Brasil. Disponível em: <http://http://sistema.datasebrae.com.br/\#sebrae>. Acesso em: 15 jul. 2017.

(2013). São Paulo, Serviço Brasileiro de apoio às Micro e Pequenas Empresas. Cartilha: o quadro de modelo de negócios. Disponível em: $<$ https://www.sebraecanvas.com.br/downloads/cartilha_canvas.pdf>. Acesso em: 15 ago. 2017.

Sperling, E. (2008). A influência da formação do preço de venda na micro e pequena empresa do comércio varejista nos relatórios gerenciais. Revista Interdisciplinar Científica Aplicada, Blumenau, v. 2(1), pp. 01-18, Sem I.

Stake, R. E. (1995). The art of case study research. Thousand Oaks, CA.: Sage.

Tófoli, I. (2008). Administração financeira empresarial: uma tratativa prática. Campinas: Arte Brasil.

Toledo Filho, J. R., Oliveira, E. L., \& Spessatto, G. (2010). Fluxo de caixa como instrumento de controle gerencial para tomada de decisão: um estudo realizado em microempresas. Revista de Contabilidade do Mestrado em Ciências Contábeis da UERJ (online), Rio de Janeiro, v. 15(2), p. 88, maio/ago. Disponível em: <http://www.atena.org.br/revista/ojs-2.2.3-08/index.php/UERJ/article/view/896/856>. Acesso em: 01 nov. 2018.

Wernke, R. (2005). Análise de custos e preço de venda. São Paulo: Saraiva. Bookman.

Yin, R. K. (2005). Estudo de caso: Planejamento e métodos. 5. ed. Porto Alegre:

\section{Para citar este artigo:}

Honorio, F., \& Bonemberger, S. (2019). Aplicação de Ferramentas de Apoio Gerencial Contábil em uma Microempresa de Confecções. REGEPE - Revista de Empreendedorismo e Gestão de Pequenas Empresas, 8(1), 201-218. doi:https://doi.org/10.14211/regepe.v8i1.1199 